
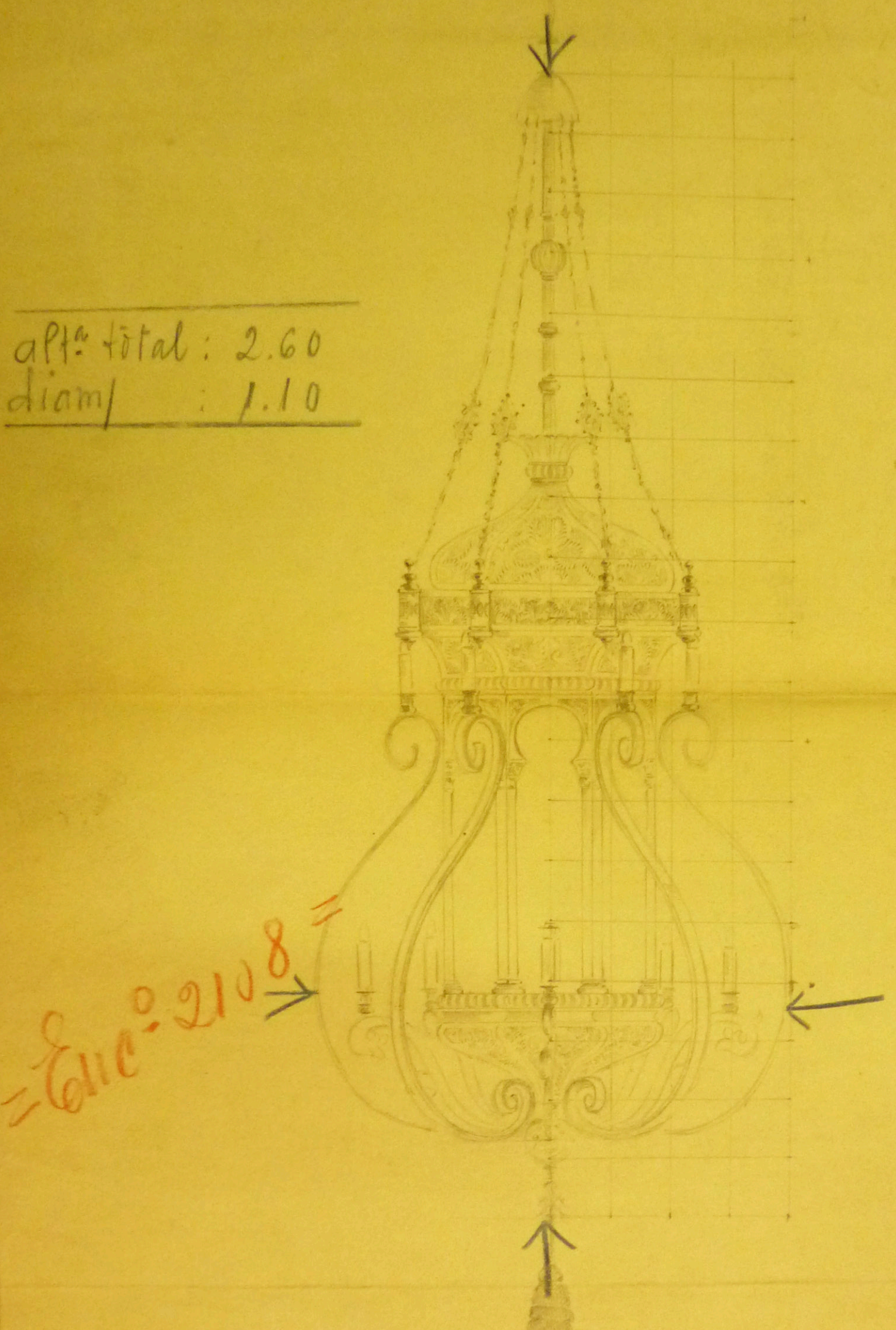

Fig. 1. Croquis n. ${ }^{\circ}$ 6. Lámpara destinada a la sala de exposición del pabellón de Córdoba, realizado por Carlos Sáez de Santa María. ADCO. Exp. HC159.1 (Clasificación antigua: leg. 4.125).

\author{
$96 \div 6-$ Erbosicion
}




\title{
Estudio histórico museográfico de la Sala Julio Romero de Torres para la Casa de Córdoba de la Exposición Iberoamericana de Sevilla de 1929
}

Historical museographic study of the exhibition room of Julio Romero de Torres for the Ibero-American Exhibition of Seville in 1929

\author{
María Dolores García Ramos \\ Universidad de Córdoba, Espańa \\ mdgarcia@uco.es \\ https://orcid.org/0000-0002-1342-7017
}

\section{Resumen}

El 18 de febrero de 1930 se inaugura el pabellón diseñado por Carlos Sáez de Santamaría para la participación de Córdoba en la Exposición Iberoamericana de Sevilla de 1929. En él se presentó un discurso articulado en torno al arte y la historia de la ciudad, en el que edificio y obras de arte actuaron como protagonistas del mismo. Un apartado destacado de este discurso lo ocupó la presencia del pintor cordobés Julio Romero de Torres, a quien se le dedicó un espacio expositivo monográfico para presentar su obra. Este artículo viene a dar cuenta de la importancia de esta

\begin{abstract}
On the 18th February 1930 the pavilion designed by Carlos Sáez de Santamaria for the participation of Cordoba in the Ibero-American Exhibition of Seville in in 1929 was opened. In this pavilion it was presented an articulated discourse about the art and history of the town, having both the building and the artworks shown acting as main characters. A highlighted section of the pavilion's discourse was focus on the presence of the painter from Córdoba, Julio Romero de Torres to whom a monographic exhibition area was devoted to display his work. In this article seeks to account for the im-
\end{abstract}


sala desde su papel histórico, situándola en el contexto del certamen, y como contribución a la práctica expositiva del momento.

Palabras clave: Exposición; museografía; museología; Julio Romero de Torres; Exposición Iberoamericana de Sevilla de 1929; Museo de Bellas Artes de Córdoba. portance of this exhibition room from its historic role, placing it in the context of the competition and in how it contributed to the exhibition practice of the moment. Keywords: Exhibition; museography; museology; Julio Romero de Torres; Ibero-American Exhibition of Seville in 1929; Fine Arts Museum of Córdoba.

La Exposición Iberoamericana de Sevilla de 1929 se sitúa en el contexto de las exposiciones universales dedicadas a las artes e industrias, en las que se dan a conocer los avances en estas áreas de las regiones participantes. Se presentan como un "escaparate al mundo de los adelantos cientificos, artísticos, comerciales..." en palabras de Solano Sobrado. Desde su origen en Francia a finales del siglo XVIII y su posterior afianzamiento en la decimonónica Inglaterra industrializada, han supuesto una gran contribución pedagógica que no tenía otro cometido que el de mostrar el progreso de la humanidad ${ }^{2}$. Además han dejado un dilatado legado histórico, social y artístico que incorpora nuevas arquitecturas y transformaciones urbanísticas a los centros que las acogen. Tal es el ejemplo de ciudades como París, Londres, Barcelona o Sevilla, por citar algunas, que tras ser sede de este tipo de acontecimientos se vieron enriquecidas sobremanera.

Como escaparates al mundo que son, las exposiciones universales se valen de una serie de mecanismos para contar esos avances y proezas históricas en las que centraban sus temáticas. El recurso empleado para tal fin es la exposición. Como es bien sabido, la exposición es el medio que museos y espacios expositivos emplean para comunicar ${ }^{3}$. Valiéndose de unos determinados instrumentos y sistemas, buscan exhibir objetos o conceptos y crear con ellos un discurso destinado a ser leído por los visitantes ${ }^{4}$. A este respecto, Juan Carlos Rico resalta el valor de las exposiciones universales al alegar que "lo curioso a nivel expositivo, es como se organiza el espacio, ya que, en vez de tomar como referencia el mundo de los museos, se toma el mundo comercial: las tiendas y las galerías" . Esta museografía a lo comercial va a aportar nuevos criterios a la práctica museográfica. De ella, como continúa Rico, toman "la concepción del diseño, las condiciones técnicas de la exposición, y el tratamiento

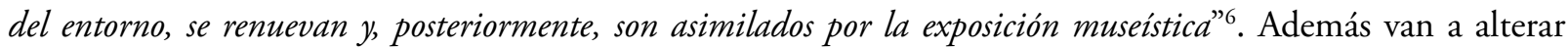
el modo en el que se establece la comunicación con el visitante, en el momento en el que se desprenden de imposiciones estéticas y del gusto de la élite, para apostar por un visitante más heterogéneo ${ }^{7}$.

La Exposición Iberoamericana de Sevilla de $1929^{8}$ se puede abordar desde la aplicación de los presupuestos planteados y el convencimiento del valor museográfico de los espacios expositivos que se

1. SOLANO SOBRADO, María Teresa, "Antecedentes históricos de la Exposición Iberoamericana de Sevilla", Cuadernos de Historia Moderna y Contemporánea, vol. 7, 1989, pág. 164.

2. RICO NIETO, Juan Carlos, La exposición comercial: tiendas y escaparatismo, stands y ferias, grandes almacenes y superficies, Gijón, Trea, 2005, págs. 42-46

3. Véase GARCÍA BLANCO, Ángela, La exposición, un medio de comunicación, Madrid, Akal, 2009.

4. DESVALLÉES, André y MAIRESSE, François (dirs.), Conceptos claves de museología, París, Armand Colin, 2010, págs. $102-103$.

5. RICO NIETO, Juan Carlos, Manual práctico de museología, museografía y técnicas expositivas, Madrid, Silex, 2006, pág. 90.

6. Ibídem.

7. DESVALLÉES, André, SCHÄRER, Martin y DROUGUET, Noémie, "Exposition", DESVALLÉES, André y MAIRESSE, François (dirs.), Dictionnaire encyclopédique de muséologie, París, Armand Colin, 2011, pág. 185.

8. Para profundizar sobre la Exposición Iberoamericana de Sevilla de 1929, véase GRACIANI GARCÍA, Amparo, La participación internacional y colonial en la exposición iberoamericana de Sevilla de 1929, Sevilla, Universidad de Sevilla, 2010; y RODRÍGUEZ BERNAL, Eduardo, La exposición ibero-americana de Sevilla, Sevilla, Ayuntamiento de Sevilla. Instituto de la Cultura y las Artes (ICAS), 2006. 
montaron para el evento. Un ejemplo relevante de esta práctica es el diseño que se ideó para la participación de Córdoba en el certamen, de cuyo pabellón hoy solo queda en pie una testimonial y descontextualizada torre en Sevilla. El interés de este espacio es múltiple, pero nosotros vamos a centrar nuestra atención en una parte de su museografía, que, una vez clausurado el certamen, se tomará como modelo para el enriquecimiento de la museología cordobesa, como demostraremos más adelante. Nos referimos al espacio que se le dedica al pintor Julio Romero de Torres (1874-1930) en la Casa de Córdoba como destacado artista cordobés contemporáneo vivo.

El objetivo de este trabajo es el estudio histórico y museográfico de la sala destinada a exponer los lienzos del mencionado artista, para concluir con la recepción que tuvo, cuya consecuencia marcará el destino que tras la clausura del certamen tuvieron tanto las obras como el diseño expositivo aquí propuesto, que no será otro que el de acondicionar un nuevo museo. Vamos a comenzar nuestra argumentación por contextualizar históricamente la presencia de Córdoba y de Julio Romero de Torres en la Exposición Iberoamericana de Sevilla de 1929.

\section{Notas históricas sobre la Exposición Iberoamericana de Sevilla de 1929} El germen de la Exposición Iberoamericana de Sevilla de 1929 tenemos que buscarlo en la muestra España en Sevilla celebrada en la capital Hispalense el 28 de abril de 1909. Con ella, en un principio, se pretendía rendir homenaje a las regiones espańolas y reforzar el sentimiento de unidad nacional, aunque terminaría tomando un carácter más ambicioso al incluir a las regiones hispanas de América. En este contexto, se propuso la celebración de una exposición -en un principio prevista para 1909 y 1910-que permitiera establecer relaciones económicas y turísticas entre los dos continentes, cuya temática abordara temas como el nacionalismo y los lazos culturales y económicos entre España e Hispanoamérica'. Además, se buscaba crear una imagen de Sevilla como una ciudad cultural alejada de los tópicos folclóricos y propiciar su desarrollo urbanístico y arquitectónico ${ }^{10}$. Más tarde, debido a la incorporación en el evento de Portugal y Brasil como activos en el Descubrimiento, se sustituyó el nombre inicial de Hispano-Americana por el de Ibero-Americana ${ }^{11}$.

La cita fue postergada en varias ocasiones. Mientras tanto, Sevilla estaba inserta en un proceso de reformas urbanísticas y arquitectónicas. Las gestiones administrativas seguían su curso: se configura la Comisión Permanente del Comité y en 1925, tras la dimisión del conde de Colombí1 ${ }^{12}$, se le otorga al cordobés José Cruz Conde el cargo de Comisario Regio, quien, de forma satisfactoria, consiguió llevar a buen fin el proyecto expositivo.

Finalmente, la Exposición Iberoamericana de Sevilla se inauguró el 9 de mayo de $1929^{13}$. La muestra estaba dividida en tres grandes secciones: Arte -antiguo y moderno-, Historia -centrada en el papel de España en el descubrimiento del Nuevo Mundo- y Comercio -destinado a los mercados entre los dos continentes $-{ }^{14}$.

\footnotetext{
9. SOlANO SOBRADO, María Teresa, "Antecedentes históricos...", op. cit., pág. 166.

10. BELLIDO GANT, María Luisa, Córdoba y la Exposición Iberoamericana de 1929, Córdoba, Diputación de Córdoba, 2001, págs. 29-30.

11. VILLA, J., "Portugal y la Exposición de Sevilla", La Voz, 20 de noviembre, 1927, pág. 3.

12. SOLANO SOBRADO, María Teresa, "Antecedentes históricos...", op. cit., págs. 179-180.

13. La Voz, 10 de mayo de 1929, págs. 1, 3, 7-8.

14. BELLIDO GANT, María Luisa, Córdoba y la Exposición..., op. cit., págs. 34-36.
} 


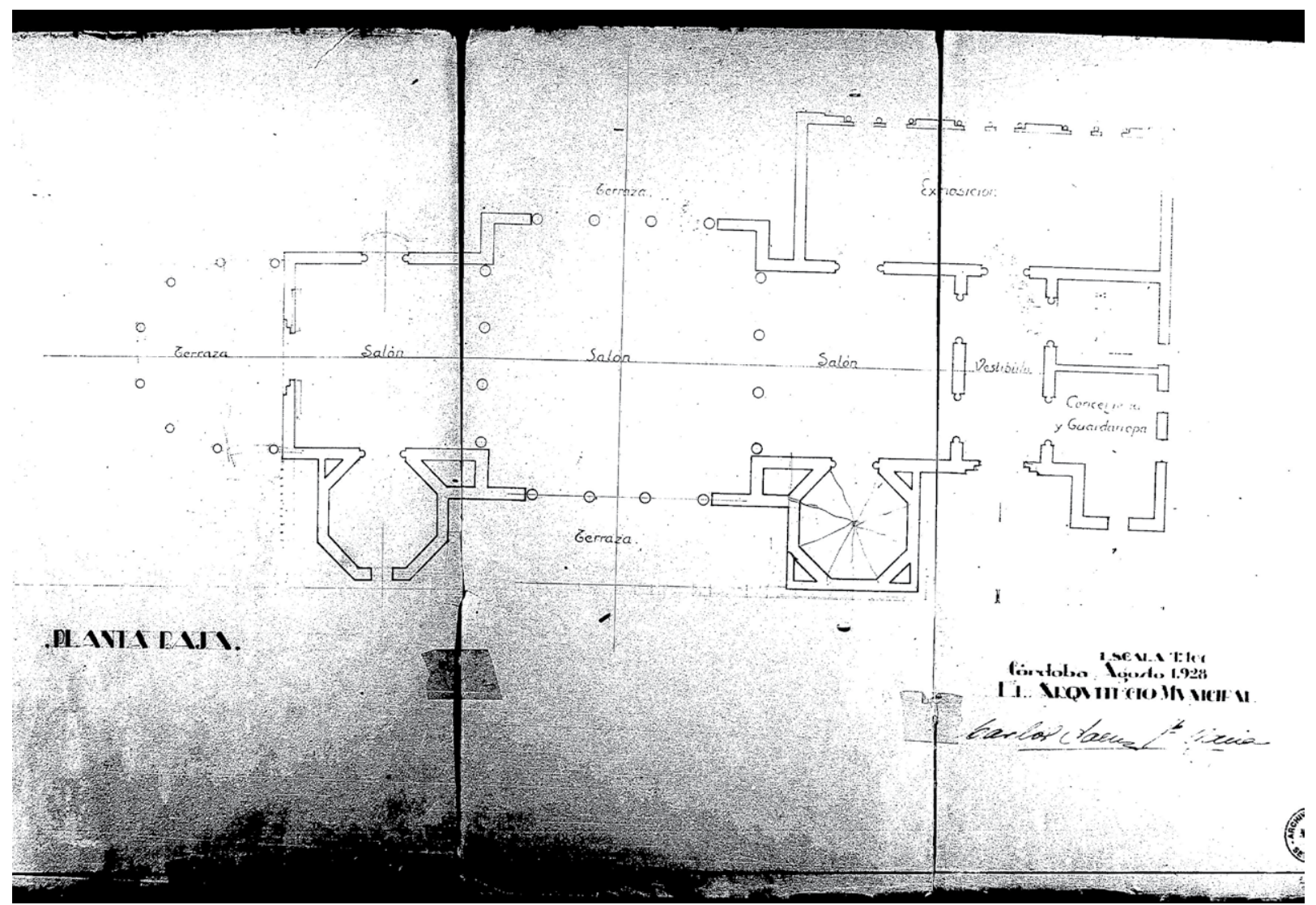

Fig. 2. Planta baja del pabellón de Córdoba. Proyecto de pabellón de Córdoba en la Exposición Ibero-Americana de Sevilla. Memoria. Rollo. 713.

El certamen se desarrolló con total normalidad y fue clausurado el 21 de junio de 1930. Pero la apertura del recinto general no implicaba que todos los pabellones estuvieran finalizados. Tal es el caso de la Casa de Córdoba, que en mayo de 1929 aún estaba en pleno proceso de construcción, labores que abordaremos en lo que sigue hasta su culminación y apertura.

\section{La Casa de Córdoba en la Exposición Iberoamericana de Sevilla}

Siguiendo la tónica de todo el certamen, la inauguración del pabellón cordobés, como venimos diciendo, también se vio demorada por titubeos en la planificación del proyecto. Las gestiones comenzaron el 12 de enero de 1928, con la aprobación por parte de la Comisión Permanente del Comité de la Exposición Iberoamericana de la participación de la ciudad y prosiguieron con la elección de los terrenos en los que construir. Los representantes del Ayuntamiento, entre los que se encontraba el alcalde de Córdoba Rafael Cruz Conde ${ }^{15}$, seleccionaron una parcela de 1.100 metros cuadrados localizada en el sector sur del conjunto, próximo al pabellón del Turismo y entre las casas de Jaén, Murcia y Asturias ${ }^{16}$.

15. Diario Córdoba, 21 de enero de 1928, pág. 1.; y Diario de Córdoba, 17 de octubre de 1928, pág. 2.

16. BELLIDO GANT, María Luisa, Córdoba y la Exposición..., op. cit., págs. 65-66. 
El proyecto del pabellón cordobés, encargado al por entonces arquitecto municipal Carlos Sáez de Santamaría, estaba ideado para reunir una serie de objetos capaces de transmitir al visitante una imagen del valor cultural, histórico y artístico de Córdoba. El discurso que se establece giraba en torno a la ciudad, su arte y su historia, temas que entroncaban a la perfección con las tres secciones marcadas por el programa general del certamen, recordemos: arte, historia y comercio.

Centrándonos en la descripción espacial del pabellón, en la memoria del proyecto se define como un edificio de dos plantas (semisótano y baja) (Fig. 2) ${ }^{17}$. También se detalla el uso de cada una de las zonas, donde el semisótano se destina a acoger la vivienda del conserje; y la baja a espacio público, que a su vez queda compartimentada en varias estancias: dos salones laterales de aire árabe, el vestíbulo de entrada, un salón de exposición destinado a la muestra de Julio Romero de Torres, la escalera, la conserjería, el guardarropa y el salón centrar que se abría al exterior por dos terrazas. Esta última sala destacaba por acoger una estructura que recreaba la Maxura de la Mezquita de Córdoba y se abría al exterior por dos terrazas. En las habitaciones localizadas en la planta baja se colocaron una serie de piezas de arte procedentes de monumentos, instituciones y colecciones cordobeses ${ }^{18}$.

Del mismo modo, los objetos que se expusieron fueron diversos: cordobanes, cueros, cornucopias, candelabros, relicarios, jarrones, lámparas de araña, objetos de plata, filigranas y todo tipo de mobiliario; documentos relativos a la historia de la ciudad; objetos arqueológicos romanos, árabes o mudéjares; y esculturas, tablas y lienzos de artistas representativos cordobeses, como Alejo Fernández, Antonio del Castillo, Valdés Leal, Pedro de Córdoba, entre otros autores ${ }^{19}$.

Respecto a la decoración del pabellón, esta se completó con un mobiliario y objetos, costeados expresamente para el evento por la Diputación de Córdoba, que venían a rematar la estética de inspiración árabe ideada por Sáenz de Santamaría para el interior del edificio. Adjunto al proyecto se conservan unos dibujoscroquis de las banquetas, sillones, divanes (Fig. 3), mesas, lámparas (Fig. 1) y plafones que se encargaron.

En otro orden de cosas, no podemos pasar por alto el protagonismo del responsable de la coordinación de todo este programa decorativo y de la selección y montaje de las piezas. En una carta que Enrique Romero de Torres, como director del Museo Provincial de Bellas Artes y como representante de la Comisión de Monumentos en Córdoba, que dirige al Delegado Regio Presidente de la Exposición Iberoamericana, Carlos Cañal, el 6 de marzo de 1930, se presenta como "instalador de la Exposición de objetos y obras de arte, en la Casa de Córdoba" ${ }^{20}$, es decir, como el comisario de la exposición del pabellón cordobés. El papel que este iba a ejercer queda igualmente confirmado por la correspondencia y documentos de gestión que se conservan en el

17. Archivo Municipal de Sevilla (AMS). Proyecto de pabellón de Córdoba en la Exposición Ibero-Americana de Sevilla. Memoria. Rollo. 713.

18. Las obras que se expusieron procedían de la Catedral de Córdoba, del Palacio de Viana, del Museo Arqueológico, del Museo Provincial de Bellas Artes, del Ayuntamiento, el Archivo de Protocolos, de la Parroquia de San Nicolás de la Villa, el Convento del Corpus Cristi, la Parroquia de San Pedro, la Parroquia de San Andrés, la Colegiata de San Hipólito, la Parroquia de San Francisco, la Parroquia de Santiago y de varias colecciones privadas de la ciudad, como las de Enrique Romero de Torres, Julio Romero de Torres, José María Rey, Ángel María Rubio, Gonzalo Fernández de Córdoba, Francisco Castillo Arlés, Pedro López Alvear, Fernanda Martel, el marqués de las Escalonias y Juan de Austria. Archivo de la Diputación Provincial de Córdoba (ADCO). exp. HC159.1 (Clasificación antigua: leg. 4.125). Exposición Ibero-Americana de Sevilla: Casa de Córdoba.

19. El envío de las piezas de Córdoba a Sevilla se realizó siguiendo el protocolo de transporte especializado de obras de arte de la época, que contemplaba un seguro por "póliza de transportes", como queda recogido en los documentos de gestión del evento. Ibídem.

20. Archivo Histórico Provincial de Córdoba (AHPCO). c. 25. leg. 7. Enrique Romero de Torres. Documentos de función. Exposición Iberoamericana de Sevilla, 1929. Correspondencia, 1928-1930. 


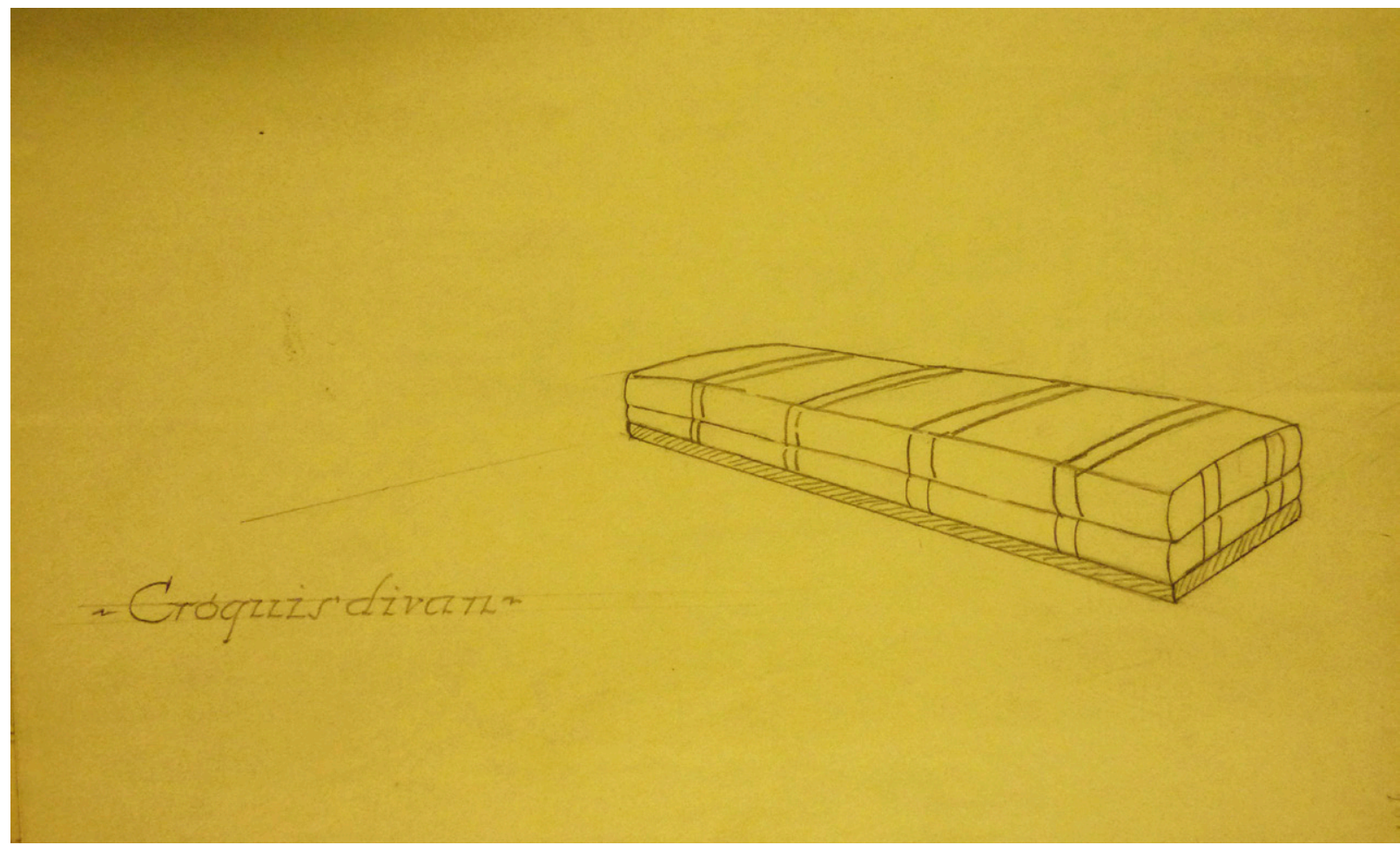

Fig. 3. Croquis de un diván destinado a decorar el pabellón de Córdoba, realizado por Carlos Sáez de Santa María. ADCO. Exp. HC159.1 (Clasificación antigua: leg. 4.125).

fondo de la Familia Romero de Torres del Archivo Histórico Provincial de Córdoba y en el Archivo Histórico del Museo de Bellas Artes de Córdoba, en los que se recoge como este se encargó de gestionar los préstamos de las obras y objetos que se expusieron en Sevilla, al igual que del diseńo escenográfico y del montaje expositivo, de los seguros, de los transportes, de los pagos a proveedores y demás labores de coordinación ${ }^{21}$.

La Casa de Córdoba aún no estaba terminada cuando se inauguró oficialmente el certamen en mayo de 1929. Las obras se dilataron más de lo deseado, pero una vez salvadas todas las incidencias, finalmente, el pabellón fue inaugurado el 18 de febrero de 1930 -a casi cinco meses de la clausura del evento- ${ }^{22}$ con todas las piezas colocadas, entre ellas, los lienzos de Julio Romero de Torres.

\section{La presencia de Julio Romero de Torres en la Exposición Iberoamericana de Sevilla} Una de las decisiones que se tomaron al inicio de la construcción del edificio de la Casa de Córdoba fue el acuerdo unánime en diciembre de 1928 por el Comité de la Exposición por el que se aprobó la participación del artista cordobés Julio Romero de Torres. En estos momentos, y desde 1915, el pintor tenía su taller y residencia instalados en Madrid. A pesar de que continuaba realizando visitas esporádicas a Córdoba, estas

21. Montero Alonso atribuye a Enrique la decoración de las salas y la prensa local recoge en repetidas ocasiones lo admirable de su labor en el pabellón. Véase MONTERO ALONSO, José, Julio Romero de Torres. Vida, arte, gloria e intimidad del gran pintor, Madrid, Compañía IberoAmericana de Publicaciones, ca. 1930, pág. 20.

22. BELLIDO GANT, María Luisa, Córdoba y la Exposición..., op. cit., págs. 68-74. 
cortas estancias no eran suficientes para atender el nuevo encargo. Es por ello que, José Cruz Conde, como comisario regio, solicita personalmente al pintor que se traslade a Sevilla para colaborar más activamente con los trabajos de montaje de la muestra de arte contemporáneo del certamen ${ }^{23}$. En este contexto, a principios de marzo de 1930 se había previsto el traslado del artista desde Madrid a Sevilla ${ }^{24}$, pero, debido a que se encontraba debilitado por el agravamiento de la enfermedad que sufría, decidió establecerse en la casa familiar de Córdoba y realizar visitas puntuales a la ciudad Hispalense.

Pero, vayamos a lo que nos ocupa. ¿Qué presencia tendría la obra de Julio Romero de Torres en la Casa de Córdoba?, y ¿cuál sería la posición del artista en el certamen? Para contestar a estas cuestiones, debemos recurrir a la correspondencia mantenida entre Enrique Romero de Torres y Carlos Cańal, antes referida, en la que el primero menciona que los cuadros del pintor no iban a competir en la sección de arte contemporáneo del concurso ${ }^{25}$. Esta exclusión de la sección oficial solo nos deja la opción de justificar su presencia en el pabellón cordobés por estar considerado un representante de la pintura contemporánea cordobesa.

Como decíamos, cuando en 1928 Rafael Cruz Conde le invita a participar en el Comité de la Exposición, Julio está plenamente instalado en Madrid. Desde la capital atenderá a todos los encargos, entre los que se encontraban los lienzos que iban a formar parte de su muestra individual. La mayoría de ellos fueron realizados en su estudio madrileńo con posterioridad a 1915. Esta circunstancia hizo necesaria la gestión de un envío adecuado y especializado de obras de arte, aprobado por la Comisión Provincial de Córdoba el 14 de enero de 1930, al hacerse cargo de los gastos derivados del seguro y el traslado de las pinturas en los siguientes términos: "Esta Comisión, en 10 del corriente mes, acordó costear los gastos del traslado de Madrid a Sevilla de las obras del pintor Julio Romero de Torres, que han de figurar en la Casa de Córdoba de la Exposición Ibero-Americana, que importan 710,55 pesetas [...]"26.

El seguro y el transponte de todas las obras se efectuó sin ningún incidente según los términos acordados, sumando un total de 29 lienzos los que fueron enviados a Sevilla como propiedad de Julio Romero de Torres $^{27}$. Así, en enero de 1930 las obras ya estaban en Sevilla. El seguro fue contratado con la compañía La Unión y El Félix Español bajo las características de lo que actualmente consideramos un "clavo a clavo", al contemplar el retorno de las obras de Sevilla a Madrid en las mismas condiciones que se habían establecido para la ida ${ }^{28}$. Pero el desarrollo de los acontecimientos tomó un rumbo inesperado. La repentina muerte de Julio Romero de Torres el 10 de mayo de 1930, cuando aún quedaba mes y medio para la clausura del

23. La Voz, 30 de diciembre de 1928, pág. 2

24. ENDERIZ, E., "Después de la muerte de Romero de Torres. La tristeza del estudio vacío", Estampa, 3 de junio, 1930, pág. 10.

25. AHPCO. c. 25. leg. 7. Enrique Romero de Torres. op. cit.

26. Archivo del Museo de Bellas Artes de Córdoba (AMBACO). c. 5. leg. 20. Oficio n. 16 de la Comisión Provincial de Córdoba remitido a Enrique Romero de Torres.

27. En el Archivo de la Diputación Provincial de Córdoba se conserva el listado definitivo de obras con la cantidad que alcanzaban sus respectivos seguros: "Rivalidad" (25.000 ptas.), "La nieta de la Trini" (15.000 ptas.), "Gitana" (8.000 ptas.), "Contrariedad" (20.000 ptas.), "Camino de bodas" (4.000 ptas.), "Desnudo" (15.000 ptas.), "En la Ribera" (10.000 ptas.), "Naranjas y limones" (10.000 ptas.), "La niña de las uvas" (10.000 ptas.), "La niña del jarro" (3.000 ptas.), "Mujer de Córdoba" (3.000 ptas.), "Carmen" (3.000 ptas.), "Nieves" (2.000 ptas.), "Fuensanta" (2.000 ptas.), "Rosarillo" (2.000 ptas.), "La niña del candil" (2.000 ptas.), "La Chiquita buena" (2.000 ptas.), "La niña de la rosa" (1.000 ptas.), "María Luz" (1.000 ptas.), "Bendición" (1.000 ptas.), "Marta" (1.000 ptas.), "Ángeles" (1.000 ptas.), "María de la O" (1.000 ptas.), "María" (1.000 ptas.), "Ofrenda al arte del toreo" (10.000 ptas.), "Muerte de Santa Inés" (12.000 ptas.), "La copla" (5.000 ptas.), "Eva" (2.000 ptas.) y "Chiquita piconera" (4.000 ptas.). Véase ADCO. exp. HC159.1 (Clasificación antigua: leg. 4.125). Exposición Ibero-Americana de Sevilla: Casa de Córdoba. Listado de objetos que se aseguran por la póliza de transportes n. 420.

28. ADCO. exp. HC159.1. Carta de 28 de Enero de 1930 de la compañía La Unión y El Fénix Español, dirigida a Enrique Romero de Torres informando de la correcta entrega de las obras. 
certamen, hizo que las obras no volvieran a Madrid y, en cambio, fueran enviadas a Córdoba por expreso deseo de la familia.

El Diario de Córdoba, en su número del 26 de junio de 1930, recoge en sus "Notas de Sociedad" la noticia de la recogida de los cuadros expuestos en el certamen sevillano por su hijo Rafael Romero de Torres Pellicer $^{29}$. No hemos localizado algún documento administrativo que certifique que el hecho del cambio del destino final iba a respetar el seguro inicialmente contratado, pero hemos de suponer que si en un principio hubo una intención de proteger la carga, en última instancia sí pudiera haberse mantenido las mismas o similares condiciones de envío a la vuelta. Esta hipótesis queda avalada por el hecho de que el grupo de objetos procedentes de Córdoba, también contaba con una póliza bastante detallada realizada por la misma compañía, cuyo contrato sí se respetó ${ }^{30}$.

Estas acciones son las que permitieron la gestión y coordinación de la muestra, y, por tanto, la puesta en sala de las obras mediante un diseño museográfico que procedemos a analizar.

\section{La sala Julio Romero de Torres: análisis museográfico}

Una vez contextualizada la presencia de Julio Romero de Torres en la Exposición Iberoamericana de Sevilla de 1929, tenemos que abordar sin más cómo se hizo la presentación en la sala de sus pinturas. Es por ello, que en lo que sigue vamos a plantear un análisis museográfico, atendiendo a su configuración espacial, discurso y escenografía.

Así, como ya vimos al estudiar la configuración espacial de la Casa de Córdoba, para exponer la obra de Romero de Torres se destinó un salón rectangular en línea con la puerta de ingreso del pabellón y a la izquierda del salón central. El propósito del arquitecto con este diseño era el de convertir la sala de exposiciones en un espacio preferente dentro del edificio. Con esto se creaba un claro recorrido dirigido hacia la sala de exposiciones, donde se propiciaba que el primer contacto con el arte cordobés que tuvieran los visitantes fuera la obra de Romero de Torres.

$\mathrm{Al}$ igual que sucede con el resto del pabellón, la Diputación Provincial fue la encargada de costear toda la decoración y ambientación escenográfica ${ }^{31}$. El salón tenía un planteamiento arquitectónico sobrio, de corte rectangular, con una techumbre plana y un pavimento de mármol blanco. El resto de enseres seguía una línea similar a la del mobiliario del resto del edificio, como especifica el informe del acta de recepción de las obras:

"Una mesa en madera de caoba barnizada, tallada y policromada, de un metro con setenta centímetros por ochenta centimetros, valorada en mil ciento cincuenta pesetas; dos divanes rectos de un metro cincuenta

\footnotetext{
29. Diario de Córdoba, 25 de junio de 1930, pág. 2.

30. ADCO. exp. HC159.1. Ibídem.

31. La escenografía entendida como práctica museográfica consiste en adecuación de los espacios interiores y de exposiciones. Gob y Drouguet la conciben como una actividad que "regroupe les aspects proprement formels et matériels de l'exposition : cimaises, couleurs, vitrines, éclairage... Les applications de la scénographie consistent à mettre en œuvre les meilleures formules pour communiquer au visiter le programme scientifique d'une exposition, à la différence de la décoration, qui utilise les collections et autres éléments de la présentation uniquement en fonction de critères esthétiques" ("reagrupa los aspectos propiamente formales y materiales de la exposición: anclajes de los cuadros, colores, vitrinas, iluminación... Las aplicaciones de la escenografía consisten en la puesta en marcha de las fórmulas de comunicación más adecuadas para visitar el programa científico de la exposición, a diferencia de la decoración, que utiliza las colecciones y otros elementos de la presentación únicamente en función de criterios estéticos". (trad. de la autora)). GOB, André y DROUGUET, Noémie, La Muséologie. Histoire, développements, enjeux actuels, París, Armand Colin, 2010, pág. 16.
} 


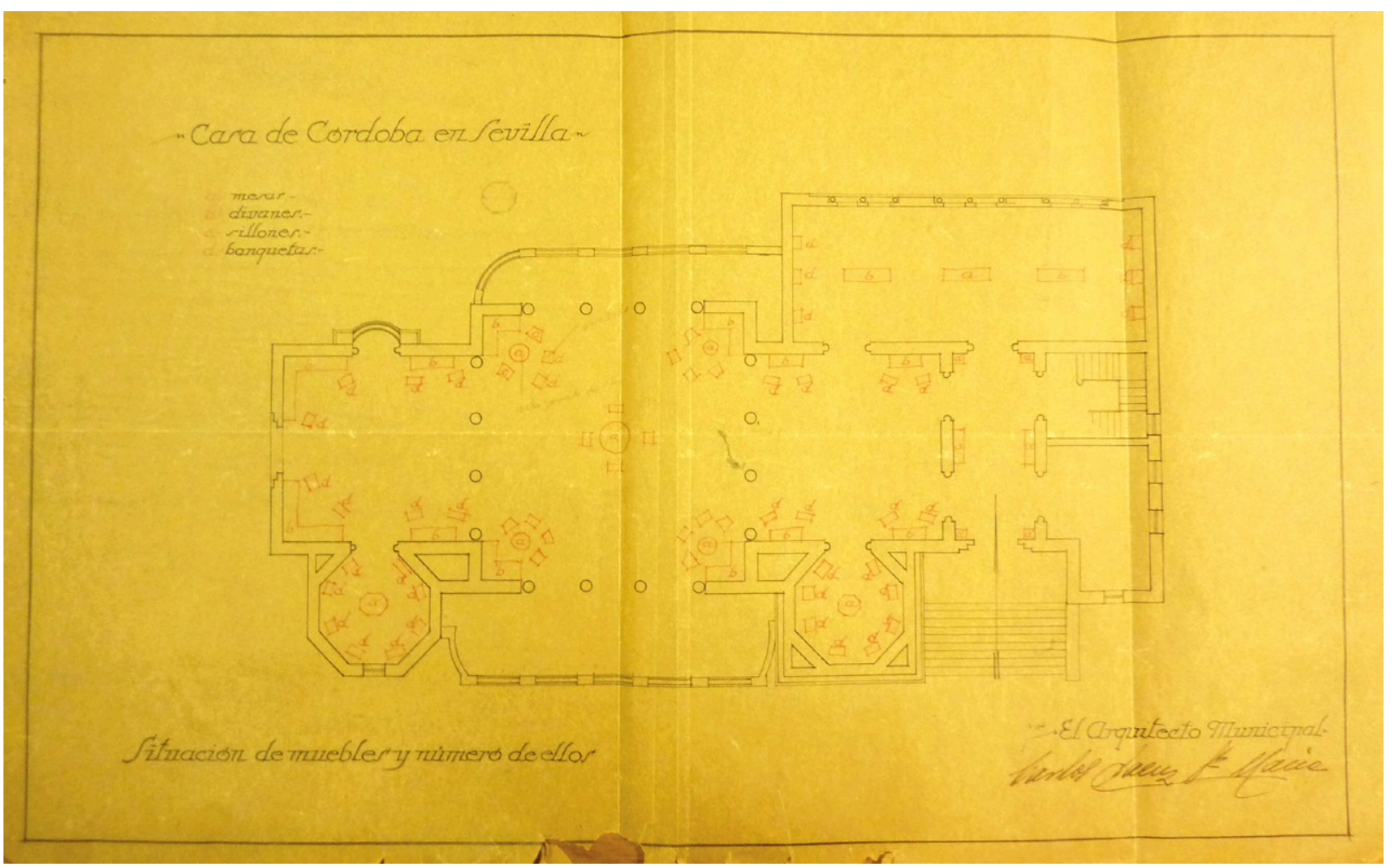

Fig. 4. Plano de la Casa de Córdoba donde se indica en letras rojas la localización del mobiliario. ADCO. ADCO. Exp. HC159.1 (Clasificación antigua: leg. 4.125).

centimetros de largo, con las mismas caracteristicas de los construidos para el salón central, pero en distinta tapicería, valorados en mil seiscientas pesetas; seis banquetas a juego con los muebles anteriores, valoradas en mil doscientas pesetas [A lo que hay que añadir tres lámparas de seis luces de estilo califal] '³2.

En los planos adjuntos a la memoria del proyecto que se conservan en el Archivo de la Diputación de Córdoba (Fig. 4$)^{33}$ se detalla la colocación y número de muebles previstos para cada sala. Contrariamente, en la única fotografía que hemos localizado de esta habitación (Fig. 6) ${ }^{34}$, no aparece todo el mobiliario anteriormente descrito. Este hecho viene justificado, como no puede ser de otro modo, por el carácter temporal de la muestra y por los cambios que pudieran haberse producido en la localización del mismo en el momento de realizar la instantánea, donde también se aprecia el uso de alfombras en el centro de la sala, a las que la documentación no hace mención alguna.

Continuando con la decoración de las paredes, esta atendía a las modas museográficas del momento: estaban cubiertas con telas encargadas a la casa Fortuny. En concreto, son brocales de color verde plata, que envolverían todo el perímetro de las salas y sobre el que se apoyaban los cuadros; y otras de color rojo oro para las cortinas y detalles a modo de cenefas en los marcos de las puertas ${ }^{35}$. 
Para poder analizar en profundidad esta exposición, ha sido de gran interés un dibujo perteneciente a la colección de la Familia Romero de Torres de la Junta de Andalucía ${ }^{36}$ que conserva entre sus fondos el Museo de Bellas Artes de Córdoba, titulado Estudio para montaje en la Exposición Iberoamericana de 1929 y atribuido a Julio Romero de Torres (Fig. $5)^{37}$. Concretamente, se trata de un apunte en el que se hace una propuesta de diseño expositivo. En él se señalan las obras a exponer y su colocación, pero también se advierten titubeos y rectificaciones, propios de una fase de conceptuación expositiva, donde vemos esquemas que no llegaron a materializarse. Es por esto, que lo consideramos como una herramienta de planificación y montaje que nos va a permitir acercarnos a este espacio desde el momento de su conceptualización y plantear una reconstrucción museográfica.

En primer lugar vamos a abordar lo relativo a la identificación de las obras desde una lectura comparada del croquis y la fotografía de la sala. Por un lado detectamos que en el dibujo hay 8 pinturas sin titular, pero representadas por la esquematización de sus marcos.

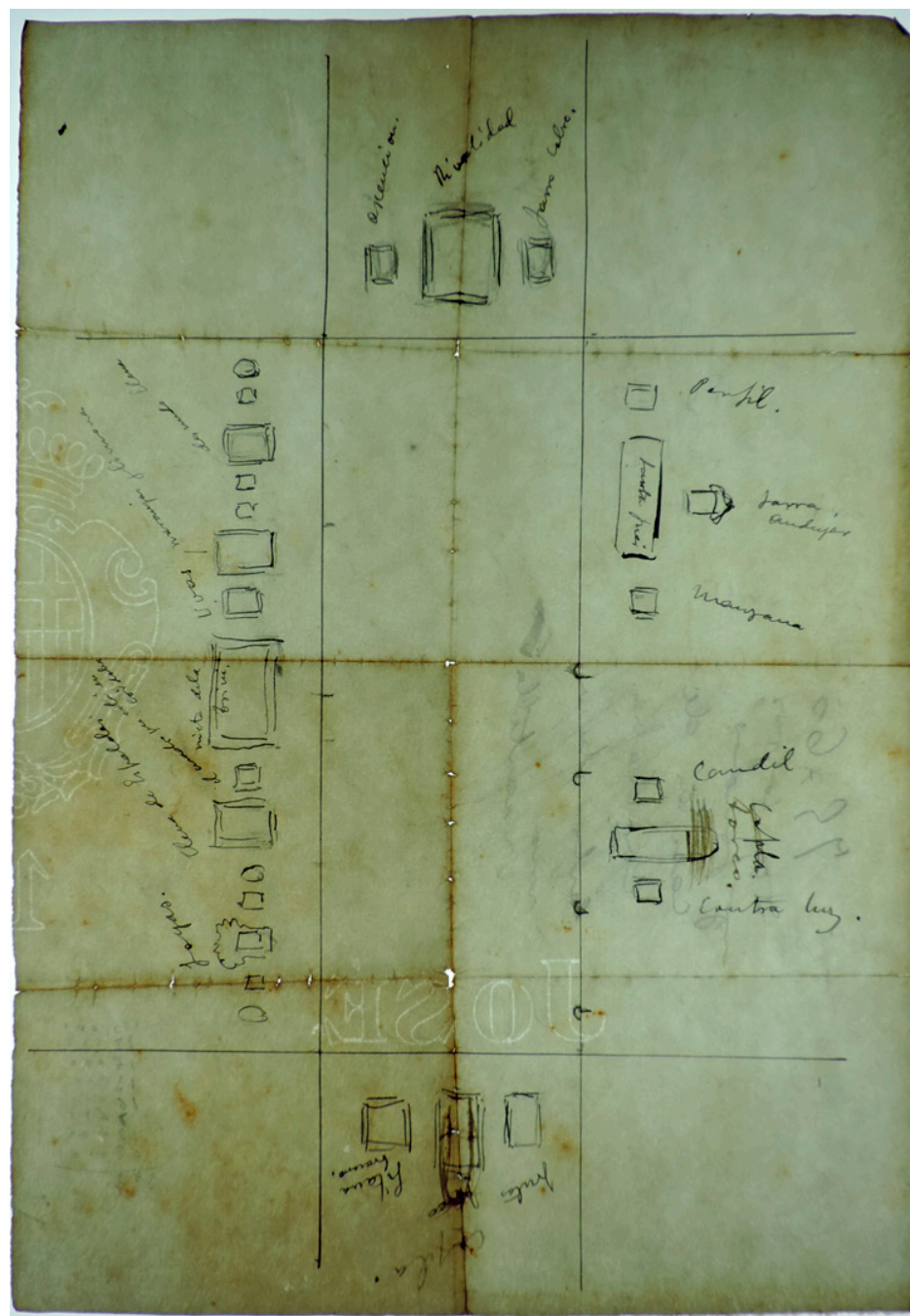

Fig. 5. Julio Romero de Torres. Estudio para montaje en la Exposición Iberoamericana de 1929. Colección Junta de Andalucía. Num. Inv. DJ0388D. ca. 1929-1930. 330 mm. x 230 $\mathrm{mm}$. Tinta, grafito y papel. Todas ellas presentan un formato similar, pequeño, que podemos vincular con los retratos femeninos -denominados chiquitas buenas por García de la Torre $^{38}$ - tan numerosos en la producción de Julio Romero. En este sentido, planteamos la hipótesis de que el interés de estas obras en el discurso expositivo no radicara en su valor individual, sino en ser testimonio de un género pictórico.

36. Julio Romero de Torres. Estudio para montaje en la Exposición Iberoamericana de 1929. Colección Junta de Andalucía. Núm. Inv. DJ0388D. ca. 1929-1930. $330 \mathrm{~mm}$. $230 \mathrm{~mm}$. Tinta, grafito y papel.

37. En la ficha catalográfica del Museo de Bellas Artes de Córdoba aparece como autor del dibujo Julio, pero no está firmado. Haciendo una comparación entre las caligrafías de Enrique y Julio Romero de Torres, creemos que, efectivamente, pueda ser de éste último. Por tanto, planteamos la hipótesis de que sea un diseño realizado en el invierno de 1929 y 1930, justo antes de su traslado definitivo a Córdoba. Esto se debe a que en las anotaciones de localización de las obras se hace referencia a "el cuadro que está en Córdoba". Independientemente de que estuviera hecho en una ciudad y otra, sí que es cierto que nos muestra un intento de planificación expositiva al ser una propuesta provisional para la instalación de los lienzos.

38. GARCÍA DE LA TORRE, Fuensanta, Julio Romero de Torres: pintor 1874-1930, Madrid, Arco, 2008, págs. 170-171. 
El resto de lienzos, un total de 20, sí están identificados, pero no se emplean los títulos marcados en el seguro de transporte, sino que aparecen referidos con una nomenclatura coloquial: señalando elementos que la distinguen, por el nombre de la modelo o por su iconografía. Pongamos el ejemplo dos obras que comparten como protagonista la modelo madrileña Elena Pardo: Desnudo y En la Ribera. Estas quedan nombradas en el croquis como Desnudo de Elena y Elena de espaldas, respectivamente. O incluso se señalan en base a su procedencia, como es el caso de "El cuadro que está en Córdoba", siendo este uno de los que no llegamos a desentrañar su correspondencia.

Otro elemento que nos habla de que nos encontramos ante un diseńo expositivo previo, es que hay titubeos a la hora de proponer el emplazamiento de los lienzos. El autor establece varias posibilidades, como ocurre con Toreo ${ }^{39}$ y Copla. Estos títulos aparecen repetidos dos veces, pero siempre uno de ellos tachado, acción que marca el lugar de colocación definitivo. También quedan dibujados los marcos y perfiles de algunas obras, como es el caso de Joyas ${ }^{40}$, Jarra de Andújar ${ }^{41}$ o Copla, cuyo formato es alargado y terminado en un medio punto.

También se hace una propuesta de recorrido. Un examen exhaustivo del dibujo nos permite advertir cuatro marcas que señalan los dos vanos de ingreso a la sala, incluso parecen estar desplazados hacia el lateral izquierdo, hecho que establece una total correspondencia con el diseño espacial de la sala manifiesto en el plano general del pabellón que ya hemos referido. De este modo, el itinerario seguido por el visitante va a estar marcado por las características espaciales de la estancia y no tanto por la creación de un posible discurso expositivo.

En lo referente al esquema compositivo empleado para la colocación de los cuadros, vemos que el discurso $^{42}$ no se centra en planteamientos temáticos ni cronológicos, sino que el criterio seguido se establece en base a las dimensiones de las obras; es decir, prevalece lo puramente estético sobre lo narrativo, se busca la contemplación y goce estético con la obra de Romero de Torres. En base a esto, hemos identificado tres tipos de esquemas que crean ritmos compositivos visuales que atienden a un criterio de ordenamiento por tamaño de los lienzos, que detallamos en lo que sigue:

- El primero de ellos, y repetido hasta tres veces, lo encontramos en los lados menores de la sala y en el espacio que queda entre las dos puertas. Se plantea un esquema en el que intervienen tres lienzos, uno central, de mayor tamaño, y dos que la flanquean, siendo estos de pequeño formato.

- El segundo, destinado al lado que queda junto a la puerta, es una derivación del primero, pero al usar una obra central de formato alargado, y por tanto de poca altura, se coloca una cuarta de menor envergadura sobre esta, para marcar un diseño triangular y así potenciar su presencia visual en la sala. - Y por último, el tercero, presente en el lado mayor que no tiene hueco, por lo que la superficie expositiva es mayor y permite acoger hasta quince lienzos. Se trata de un esquema que también

\footnotetext{
39. La nomenclatura de Toreo en el croquis remite a Ofrenda al arte del toreo.

40. En el croquis aparece una obra nombrada como Joyas, pensamos que puede estar haciendo referencia a Contrariedad, ya que la modelo porta un cuadro que representa un joyero con joyas, y por la decoración vegetal del marco, que queda bien remarcada en el croquis.

41. Pensamos que Jarra de Andújar corresponde con la Niña de la jarra o del jarro, tanto por la evidencia del título como por el esquema del marco que se representa en el croquis.

42. En un contexto expositivo, el término discurso se vincula a la definición de la exposición como espacio de comunicación, que utiliza un lenguaje que pone a disposición de sus visitantes lectores una narración o historia a lo largo de un recorrido o circuito. Véase HERNÁNDEZ HERNÁNDEZ, Francisca, "El discurso museológico y la interpretación crítica de la historia", ICOFOM Study Series, 35, 2006, págs. 300-301; y DESVALLÉES, André y MAIRESSE, François (dirs.), Dictionnaire..., op. cit., pág. 794.
} 
juega con los tamaños, donde se crea un ritmo simétrico que fluye desde el exterior hasta el centro, consistente en dos cuadros pequeños, uno mediano, dos pequeños, uno mediano, uno mediano y el central de gran formato.

La importancia del dibujo va más allá de ser la constancia documental del proceso de creación de la muestra. Más bien, radica en que se nos está ofreciendo el diseño de unos esquemas expositivos que, aunque con otras obras, será el que se llegue a materializar en el montaje definitivo de la sala de Julio Romero de Torres en Sevilla.

Como venimos diciendo, solo hemos localizado una fotografía (Fig. 6) del interior de este espacio. En ella se muestran las obras ya expuestas y se puede apreciar que muchos de los planteamientos propuestos en el croquis están presentes. Así el diseño museográfico basado en la creación de ritmos mediante la agrupación de obras por tamaño y formato de los lienzos, se mantuvo prácticamente en su totalidad. A pesar de este respecto a la idea inicial, se hacen evidentes algunas modificaciones relativas al listado definitivo de las obras y al emplazamiento final de las mismas. Tal es el caso de la decisión definitiva que presenta el lado mayor situado frente a las puertas de acceso. Aquí advertimos una alteración leve en el grupo central. En el dibujo se propone para este espacio La Nieta de la Trini flanqueado por dos retratos femeninos, esquema que se varía en el montaje definitivo al sustituirlos por La Muerte de Santa Inés con La Niña de la Jarra en la parte superior, pero se mantiene el ritmo con los retratos de las chiquitas buenas a los lados que se intercalan a su vez con lienzos de formato mediano.

La Muerte de Santa Inés, como ya hemos visto al analizar el croquis, es uno de los que se proponía para el otro lado mayor de la sala, por lo que planteamos la hipótesis de que a este espacio pudiera haberse destinado La Nieta de la Trini, para asegurar una simetría estética estricta basada en el enfrentamiento de dos grupos de tres obras. Aunque no tenemos imágenes del resto de la sala, siguiendo los criterios y las pautas de comportamiento analizados, pensamos que no pudiera haberse producido alteraciones relevantes respecto al planteamiento del croquis.

El resultado final del montaje marca una colocación de las obras que no dejaba mucho espacio entre ellas, colocándolas con bastante proximidad, sin contar aún con unos criterios expositivos que propicien la individualización visual de las piezas.

Por último, en lo referente a la iluminación, esta era artificial, resuelta con tres lámparas de seis luces cada una colgadas del techo (Fig. 1) ${ }^{43}$, tal y como aparece marcado en el plano de situación de lámparas de Carlos Sáez de Santamaría y como describe el acta de recepción de obras y mobiliario en la Casa de Córdoba ${ }^{44}$.

43. En la documentación relativa a la Casa de Córdoba de la Exposición Iberoamericana de Sevilla perteneciente al Archivo de la Diputación de Córdoba se conserva un dibujo de una de las lámparas destinadas a la sala de exposición. Este diseño coincide con la lámpara que se puede ver en la fotografía de la sala. ADCO. Exp. HC159.1. Croquis n. ${ }^{\circ}$ 6. Lámpara destinada a la sala de exposición del pabellón de Córdoba, realizado por Carlos Sáez de Santa María.

44. ADCO. exp. HC159.1. Planos de la situación de los muebles y número de ellos en la Casa de Córdoba. Y acta de recepción de las obras en la Casa de Córdoba, 10 de enero de 1930. 


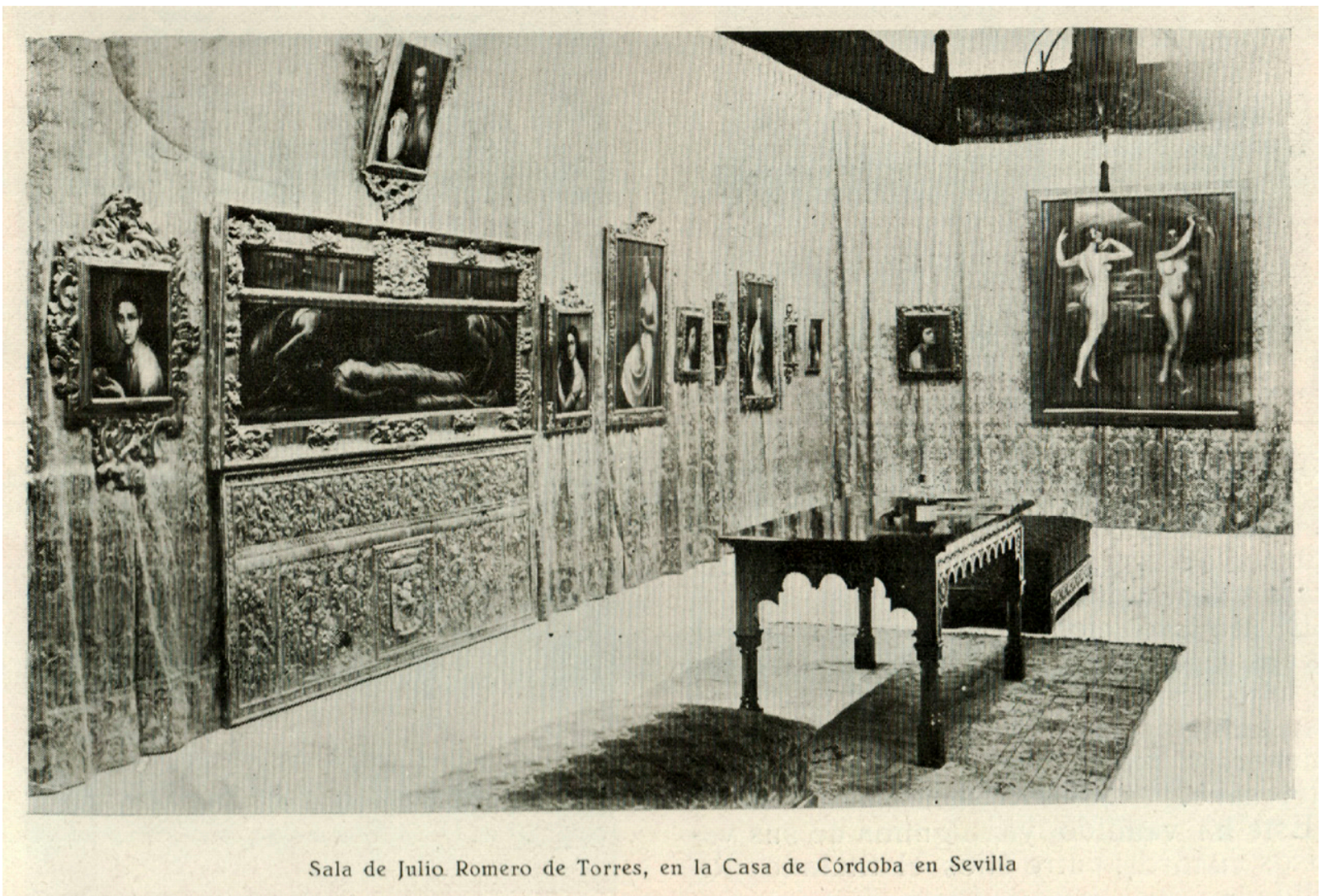

Fig. 6. Fotografía del interior de la sala Julio Romero de Torres de la Casa de Córdoba. Comercio de Córdoba. Gran Feria de Nuestra Señora de la Salud, n. ${ }^{\circ} 9,1930 . \mathrm{s} / \mathrm{p}$.

Recepción de la sala de Julio Romero de Torres Para finalizar con nuestro estudio sobre la sala de Julio Romero de Torres, tenemos que reflexionar sobre la recepción que tuvo en el contexto de la cita sevillana. Según las crónicas, esta fue uno de los espacios más visitados del pabellón. La repentina muerte del pintor, con sus obras aún expuestas, hizo que se generase una fuerte expectación que supuso un aumento considerable de los visitantes que se interesaban por la Casa de Córdoba. La prensa también se hizo eco del acontecimiento, se volcó en sus valoraciones sobre el trabajo del pintor y se afirmaba que era el espacio más visitado de todo el certamen, como se deducen de las palabras de José Montero Alonso: "En la Casa de Córdoba el éxito de Julio Romero constituye la nota principal de la Exposición Iberoamericana”45; aunque creemos que puede llegar a ser una afirmación un poco sobredimensionada.

Otra muestra del éxito inaudito que las obras aquí presentadas estaban cosechando fue el interés que muchos mostraron por adquirir alguno de los lienzos expuestos. Julio Romero de Torres, ya sea directamente o a través de su hermano Enrique Romero, había recibido varias ofertas de compra en los primeros meses del certamen. La más destacada, sin ser la única, fue la que efectuó el médico argentino Arturo Uriarte, quien

45. MONTERO ALONSO, José, Julio Romero de Torres..., op. cit., pág. 21. 
expresó su deseo de hacerse con cuatro lienzos. Este pudo haber tenido ya contacto con la obra del pintor en la exposición que la galería bonaerense Wittcober le dedicó en 1926. Afortunadamente para el coleccionista el contrato de compra llegó a materializarse y tras la clausura de la muestra cuatro obras -Rivalidad, Esclava o Desnudo de mujer, Amparo o Gitana y La niña de las uvas- viajaron para Argentina.

Por otra parte, por algunas noticias un tanto confusas que recoge la prensa local del momento, tenemos indicios de que una quinta obra pudiera haber sido vendida. Se trata de María ${ }^{46}$, que posiblemente fuera adquirida por una peruana llamada Isabel Salcedo por 5.000 pesetas. Pero debido a que este hecho es totalmente ajeno a la documentación de gestión y por la vaguedad de las referencias existentes, pensamos que el contrato de venta de este retrato se canceló finalmente, como el resto de procesos de adquisición iniciados con anterioridad a la muerte de Julio Romero, entre los que se encontraba la oferta por dos cuadros realizada por un norteamericano ${ }^{47}$.

Como era lógico, los intentos de compra se incrementaron en los meses siguientes a mayo de 1930 y muchas instituciones y coleccionistas particulares alzaron sus propuestas a la familia, pero el celo de los herederos por mantener la obra agrupada y por no desprenderse de nada continuó férreo.

En este sentido, la primera reunión que celebró el Patronato del Museo Provincial de Bellas Artes tras la muerte del pintor fue esencial para concretar el destino de la colección que aún se aguardaba en Sevilla. Dicha reunión tuvo lugar el 22 de julio de 1930 y estuvo presidida por Manuel Enríquez Barrios. Según indican las actas de la sesión, en ella se informó a los allí presentes del fallecimiento de Julio Romero de Torres. Igualmente, se recogen las palabras de Enrique Romero de Torres, como representante de la familia, en las que se da cuenta de la intención de esta de depositar la colección de obras en el Museo de Córdoba "para que de esta manera, puedan ser admiradas por propios y extraños en la misma ciudad en que nació y murió el llorado artista ${ }^{348}$. De esta manera, la sala Julio Romero de Torres de la Casa de Córdoba tendría continuidad en un contexto museográfico permanente que excede el certamen sevillano.

Cecilio Barberán, en su obra Julio Romero de Torres de 1947, nos da las claves para entender cuál sería el destino final de esta exposición:

"La sala de Romero de Torres, en la Casa de Córdoba, de la Exposición Iberoamericana de Sevilla, fue un anticipo de la sala museal que no habia de tardar mucho tiempo en abrirse para su obra. Como presintiendo la cercana hora de la muerte de Romero y el aventamiento de todas las cenizas de la humana rivalidad que se pudieran oponer a la consagración museal de su obra, esta sala encaminó la atención de todos hacia la formación del Museo de Romero de Torres" ${ }^{\prime \prime 9}$.

\footnotetext{
46. En documentos de gestión del Museo Provincial de Bellas Artes, de Diputación, en los relativos a la Casa de Córdoba de la Exposición lberoamericana de Sevilla de 1929 o en la correspondencia que Enrique mantenía con diversas instituciones y participares no hay constancia alguna de un supuesto ofrecimiento y contrato de compra de un retrato titulado María. Pero la prensa local sí que se hace eco de la noticia reiteradas veces, hecho que nos hace pensar, que, posiblemente, hubiera habido un ofrecimiento de compra, pero que no se llegase a efectuar. Del mismo modo, el hecho de que se trate solo de un retrato y de poco valor hace que la repercusión de su supuesta salida de España quedara ensombrecida.

47. BARBERÁN BARBERÁN, Celio, Julio Romero de Torres. Su vida, su obra y su museo, Madrid, Afrodisio Aguado, 1947, pág. 132.

48. AMBACO. c. 18, leg. 61. Actas del Patronato del Museo Provincial de Bellas Artes de Córdoba (APMPBACO), 22 de julio de 1930.

49. BARBERÁN BARBERÁN, Celio, Julio Romero de Torres..., op. cit., págs. 132-133.
} 
En suma, el montaje de la sala de Julio Romero de Torres para la Exposición de 1929 puede ser entendido como un ensayo de lo que en un año se materializó en Córdoba en la Sala Museo Julio Romero de Torres, inaugurada el 23 de noviembre de 1931 al amparo del Museo Provincial de Bellas Artes de Córdoba. No solo las obras que aquí se expusieron terminaron rellenando el espacio que se le dedica en Córdoba, sino que parte del mobiliario y de la decoración también lo hicieron. La museografía seguida en Sevilla también viaja al nuevo recinto museístico, donde se mantuvieron los mismos esquemas escenográficos en la instalación de las piezas, con algunas variaciones propias de la necesidad de adaptarlo a otro espacio.

\section{Bibliografía}

BARBERÁN BARBERÁN, Celio, Julio Romero de Torres. Su vida, su obra y su museo, Madrid, Afrodisio Aguado, 1947.

BELLIDO GANT, María Luisa, Córdoba y la Exposición Iberoamericana de 1929, Córdoba, Diputación de Córdoba, 2001.

DESVALLÉES, André y MAIRESSE, François (dirs.), Conceptos claves de museología, París, Armand Colin, 2010.

DESVALLÉES, André y MAIRESSE, François (dirs.), Dictionnaire encyclopédique de muséologie, París, Armand Colin, 2011.

GARCÍA BLANCO, Ángela, La exposición, un medio de comunicación, Madrid, Akal, 2009.

GARCÍA DE LA TORRE, Fuensanta, Julio Romero de Torres: pintor 1874-1930, Madrid, Arco, 2008.

GOB, André y DROUGUET, Noémie, La Muséologie. Histoire, développements, enjeux actuels, París, Armand Colin, 2010.

GRACIANI GARCÍA, Amparo, La participación internacional y colonial en la exposición iberoamericana de Sevilla de 1929, Sevilla, Universidad de Sevilla, 2010.

HERNÁNDEZ HERNÁNDEZ, Francisca, "El discurso museológico y la interpretación crítica de la historia”, ICOFOM Study Series, 35, 2006, págs. 297-305.

MONTERO ALONSO, José, Julio Romero de Torres. Vida, arte, gloria e intimidad del gran pintor, Madrid, Compañía Ibero-Americana de Publicaciones, 1930.

RICO NIETO, Juan Carlos, La exposición comercial: tiendas y escaparatismo, stands y ferias, grandes almacenes y superficies, Gijón, Trea, 2005.

RICO NIETO, Juan Carlos, Manual práctico de museología, museografía y técnicas expositivas, Madrid, Silex, 2006.

RODRÍGUEZ BERNAL, Eduardo, La exposición ibero-americana de Sevilla, Sevilla, Ayuntamiento de Sevilla. Instituto de la Cultura y las Artes (ICAS), 2006.

SOLANO SOBRADO, María Teresa, "Antecedentes históricos de la Exposición Iberoamericana de Sevilla”, Cuadernos de Historia Moderna y Contemporánea, vol. 7, 1989, págs. 163-187.

Fecha de recepción: 06/02/2018

Fecha de aceptación: 12/04/2018 